\title{
Ensino de Nanociência e Nanotecnologia: perspectivas manifestadas por professores da educação básica e superior
}

\author{
Teaching Nanoscience and Nanotechnology: perspectives \\ manifested by teachers in basic and higher education
}

\author{
Mauri Luís Tomkelski ${ }^{1}$ \\ https://orcid.org/0000-0001-6395-7086 \\ Greice Scremin ${ }^{2}$ \\ https://orcid.org/0000-0002-5686-9392 \\ Solange Binotto Fagan ${ }^{2}$ \\ https://orcid.org/0000-0002-8719-4228
}

\begin{abstract}
Resumo: Este artigo evidencia e discute as perspectivas de inserção de tópicos de Nanociência e Nanotecnologia $(\mathrm{N} \& \mathrm{~N})$ no ensino, na visão de professores. Para tanto, apoia-se nos resultados de pesquisa de natureza qualitativa, com base na análise de conteúdo, realizada com professores de matemática e de ciências da natureza dos ensinos médio e superior. Além disso, foram analisados documentos legais das áreas de $\mathrm{N} \& \mathrm{~N}$, nos quais esses tópicos são referenciados. Os resultados apontam três perspectivas de inserção dos tópicos de N\&N nas práticas profissionais: abordagem de base para desenvolver um conteúdo, integrada a um conteúdo curricular, e suplementar às atividades de sala de aula. Nesta última perspectiva, o professor busca suplementar abordagens de sala de aula com atividades extraclasse em que é possível aprofundar os conhecimentos, com ênfase em ciência e tecnologia. Existe, portanto, amparo legal para a inserção destes tópicos de $\mathrm{N} \& \mathrm{~N}$, bem como necessidades sociais, econômicas e ambientais emergentes que carecem de formação profissional compatível e, consequentemente, de mais investimentos na área de educação.
\end{abstract}

Palavras-chave: Nanociência. Nanotecnologia. Ensino médio. Ensino superior.

\begin{abstract}
This article addresses and highlights the possibilities for the insertion of Nanoscience and Nanotechnology $(\mathrm{N} \& \mathrm{~N})$ topics in teaching, according to teachers' views. To do so, the article centers on the results of a qualitative study based on content analysis, which was carried out with mathematics and natural science teachers in secondary and higher education. In addition, required curriculum documents were analyzed which concern these fields of knowledge and cover those specific topics. The results point to three perspectives for the insertion of N\&N topics in professional practices: a basic approach to developing content, integrated curricular content, and supplementary classroom activities. In this last perspective, the teacher seeks to supplement classroom approaches with extra class activities in which it is possible to deepen knowledge, with an emphasis on science and technology. Therefore, there is legal support for the insertion of N\&N topics, as well as emerging social, economic and environmental needs that require compatible professional training and, consequently, more investments in education.
\end{abstract}

Keywords: Nanoscience. Nanotechnology. Secondary school. Higher education.

\footnotetext{
${ }^{1}$ Universidade de Lisboa, Instituto de Educação, Lisboa, Portugal. E-mail: mauriluis@campus.ul.pt

${ }^{2}$ Universidade Franciscana, Programa de Pós-Graduação em Ensino de Ciência e Matemática, Santa Maria, RS, Brasil.
} 


\section{Introdução}

Atualmente, algumas áreas do conhecimento estão se destacando em diferentes esferas da sociedade contemporânea por suas contribuições, as quais têm propiciado impacto na qualidade de vida das pessoas e nas distintas práticas profissionais. A título de exemplo podemos citar a aplicação dos conhecimentos da ciência e da tecnologia na área da saúde, a qual se utiliza de materiais com potencial biológico para o tratamento e diagnóstico de doenças, realização de cirurgias e exames mais eficientes, bem como no desenvolvimento de dispositivos, tais como próteses e fármacos mais específicos e próximos da realidade. Além disso, esses conhecimentos têm ampla aplicação nas áreas da estética e cosmética, especialmente a tecnologia nanoscópica ${ }^{3}$. Esses exemplos evidenciam a presença da Nanociência na vida cotidiana das pessoas e, principalmente, sua aplicação, denominada Nanotecnologia, conceitos estes relacionados ao desenvolvimento de dispositivos diversificados com ampla utilização em todas as áreas do conhecimento e campos profissionais.

Também no âmbito da educação, especificamente no que concerne ao ensino das ciências da natureza e da matemática, as descobertas e as aplicações advindas do desenvolvimento de dispositivos diversos têm impactado nos processos educacionais. Essas descobertas têm, assim, solicitado mudanças nos documentos orientadores da educação em nível nacional. Nesta perspectiva, os processos educacionais precisam incorporar tópicos diversos que advém dos avanços científicos, a exemplo dos conceitos de Nanociência e Nanotecnologia.

Diante desses aspectos e, considerando as possibilidades e implicações destes conceitos em todos os ramos da atividade humana, uma importante questão emergiu: Quais as perspectivas de abordagem da Nanociência e Nanotecnologia (N\&N) evidenciadas por professores do ensino médio e superior? Mobilizados por essa interrogação, realizamos uma pesquisa com professores das áreas de ciências da natureza e da matemática, em exercício/atuação no ensino médio e/ou superior, com o objetivo de evidenciar as perspectivas de abordagem dos tópicos de N\&N nas práticas profissionais desses professores (TOMKELSKI, 2017). A pesquisa envolveu professores de diferentes regiões do Brasil, os quais colaboraram com o estudo respondendo a um questionário online. Optamos por envolver apenas professores das áreas das ciências da natureza e matemática por considerar que tais áreas têm sido mais influenciadas pelo desenvolvimento da N\&N e, portanto, têm solicitado mais fortemente dos professores a incorporação destes conceitos em suas práticas profissionais. E, por fim, julgamos que o impacto destes conceitos é um fenômeno global com a necessidade de considerar esta questão em nível nacional.

A pesquisa que realizamos, de natureza qualitativa, baseou-se em uma análise de conteúdo (BARDIN, 2011) sobre os documentos orientadores do ensino das ciências naturais e da matemática nos referidos níveis de ensino (BRASIL, 1996, 2000a, 2000b, 2002, 2012, 2013, 2015) e, especialmente, sobre os dados constituídos mediante a aplicação de um questionário semiestruturado, dirigido a professores destas áreas e níveis de ensino.

\footnotetext{
${ }^{3}$ Medida em nanômetros: milionésimos de milímetros.
} 


\section{Contextualização temática e teórica do estudo}

A ciência se apresenta ao homem desde sua origem quando buscava entender o mundo ao seu redor e lidar com os fenômenos que se manifestam e com os mistérios do desconhecido. Sobre isto Chibeni (2011, p. 1) afirma que o "conhecimento primitivo é motivado por algo externo à atividade cognitiva propriamente dita: a necessidade de controle dos fenômenos naturais, com vistas à própria sobrevivência biológica".

Nesta perspectiva, podemos afirmar que a ciência busca permanentemente soluções para problemas científicos de naturezas diversas, principalmente os problemas da sociedade contemporânea e, neste contexto, as tecnologias têm deflagrado mudanças na vida das pessoas do ponto de vista social, econômico e cultural. Além disso, o desenvolvimento de novos conhecimentos e soluções para problemas da vida cotidiana têm propiciado a criação de novas subáreas do conhecimento e, também, áreas profissionais, impactando de maneira significativa nas práticas sociais e no mundo do trabalho.

Em face a essas inovações e possibilidades, emergem importantes conceitos nomeadamente a Nanociência e a Nanotecnologia. Segundo Murrielo, Contier e Knobel (2006, p. 2), a Nanociência tem sido apontada como uma ciência nova, entretanto o estudo de elementos em escala nanométrica antecede ao uso desta denominação, uma vez que o "desenvolvimento de instrumental apropriado para observar e manipular esses elementos teve um forte impulso nas últimas duas décadas levando ao surgimento de uma nova tecnologia que aparece no cenário como sua carga de promessas e incertezas". A nanotecnologia, por sua vez, refere-se à engenharia de materiais a "partir de átomos e moléculas, que possibilita o uso dos resultados da Nanociência para a manipulação e reorganização de nanopartículas, promovendo outras combinações e, com isso, a elaboração de novos materiais e dispositivos" (MURRIELO; CONTIER; KNOBEL, 2006, p. 2).

Fillipponi e Sutherland (2013) destacam que a Nanociência está propiciando à ciência um novo salto evolutivo, possibilitando novas rupturas científicas, porque estuda os fenômenos que envolvem a manipulação de materiais em escalas atômicas, moleculares e macromoleculares, nas quais as propriedades das escalas menores apresentam diferenças significativas das registradas nas escalas maiores.

A Nanotecnologia, segundo Fillipponi e Sutherland (2013), refere-se ao desenho, a maquiagem, a produção e aplicação de estruturas, dispositivos e sistemas de controle da forma e tamanho em escalas nanométricas ${ }^{4}$, os quais são baseados na manipulação, controle e integração dos átomos e moléculas na formação de materiais, estruturas, componentes e sistemas em nanoescalas ${ }^{5}$. Em outras palavras, é a aplicação da Nanociência em dispositivos

\footnotetext{
${ }^{4}$ Relativo a nanômetro ou a dimensões da ordem dos bilionésimos do metro.

${ }^{5}$ Mede entre 1 e 100 nanômetros (nm) em pelo menos uma de suas dimensões, observada com equipamentos específicos - microscopia de varredura. Nessa escala muitos materiais comuns apresentam propriedades diferentes das observadas em situações macroscópicas, como a baixa resistência elétrica, alterações nas cores, ponto de fusão mais baixo, entre outras. Essa alteração é decorrente do aumento a área superficial apresentada por sistemas nanométricos.
} 
moldados, mais práticos, facilitando a distribuição, acesso e utilização pela sociedade contemporânea (FILLIPPONI; SUTHERLAND, 2013, p. 19-29). Com isso, a Nanotecnologia tem sido considerada uma área promissora, uma vez que sua utilização na produção de novos dispositivos tecnológicos pode transformar a vida da sociedade contemporânea, revolucionando nossa forma de viver, de nos comunicarmos e trabalharmos (TOMA, 2009).

Além disso, atualmente evidencia-se grande usabilidade e aplicabilidade da Nanotecnologia nas diversas áreas do conhecimento, pois ela [a Nanotecnologia] manifestase e favorece a relação interdisciplinar entre áreas devido às possibilidades de convergência advindas das manipulações em nível de nanoescala, originando, com isso, novos produtos e implicações na vida humana (ZANELLA et al., 2009). As autoras complementam que dentre as diversas áreas do conhecimento, a física, a química, a biologia, a matemática, a computação, as engenharias, a ética e a legislação, a ciência da saúde, a economia e o meio ambiente são áreas fortemente favorecidas nessa relação multidisciplinar.

Nesse sentido, as áreas do conhecimento tornam-se contextos que podem favorecer a aplicação e o desenvolvimento de inovações tecnológicas específicas de cada área, bem como na pesquisa de novas nanoestruturas ${ }^{6}$, as quais promovem manipulações diferenciadas, recursos biológicos mais ativos, levando ao surgimento de novos nanomateriais (material natural, incidental ou fabricado), que contêm partículas num estado desagregado ou na forma de um agregado ou de um aglomerado, e em cuja distribuição número-tamanho $50 \%$ ou mais das partículas têm uma ou mais dimensões externas na gama de tamanhos compreendidos entre $1 \mathrm{~nm}$ e $100 \mathrm{~nm}$. Em casos específicos e sempre que tal se justifique devido a preocupações ambientais e ligados à saúde, segurança e competitividade, o limiar da distribuição número-tamanho de $50 \%$ pode ser substituído por um limiar compreendido entre 1 e 50\% (COMISSÃO EUROPEIA, 2012) e elaboração de modelos virtuais mais eficientes e dinâmicos.

Sobre isso, um relatório da Comissão das Comunidades Europeias afirma que são muitos os benefícios dos nanomateriais, desde salvar vidas até avanços que permitem novas aplicações ou a redução dos impactos ambientais. Complementa que a "nanotecnologia tem sido identificada como tecnologia facilitadora essencial” (COMISSÃO EUROPEIA, 2012, p. 3), fornecendo base para inovação e novos produtos. Em síntese, algumas áreas são mais promissoras na aplicação da Nanotecnologia, neste caso as ciências da saúde que se utilizam dos nanomateriais com potencial biológico para o tratamento e diagnóstico de doenças e, também, em aplicações estéticas e cosméticas.

Além dos benefícios evidenciados, de acordo com Zanella et al. (2009) e corroborando a Toma (2009), tem se tornado pertinente e necessário discutir sobre os impactos da utilização das nanoestruturas sintéticas no meio ambiente, bem como a adequação e/ou elaboração de legislações e questões éticas adequadas para o uso da Nanotecnologia, uma vez que essas nanoestruturas podem trazer consequências sociais, humanas, ambientais e econômicas. Tais aspectos, evidentemente, trazem implicações aos processos educacionais em todos os níveis de ensino, uma vez que se faz necessário promover discussões e reflexões sobre as possibilidades e impactos destes recursos. Esses aspectos sinalizam mudanças em termos das Orientações

\footnotetext{
${ }^{6}$ Estruturas constituídas ou constituintes de partículas nanométricas na ordem dos bilionésimos do metro.
} 
Curriculares para o ensino e, sobretudo, nas práticas profissionais dos professores, de modo que o estudo sobre a inserção de tópicos como a N\&N é relevante no sentido de que pode apontar caminhos para a concretização de mudanças educacionais em diferentes níveis de ensino.

\section{Metodologia}

A pesquisa, de natureza qualitativa segundo entendimento de Creswel (2014), foi conduzida mediante o objetivo de evidenciar as perspectivas de inserção dos tópicos de N\&N no ensino médio e superior, evidenciadas por professores das ciências naturais e da matemática atuantes nestes níveis de ensino. O estudo baseou-se nos dados constituídos por meio de questionário semiestruturado online, respondido por professores dessas áreas e níveis de ensino.

O questionário constituiu-se de vinte questões centrais, algumas com perguntas complementares, e foi estruturado em duas partes: a primeira parte composta por dez questões para definir o perfil do participante (pessoal, acadêmico e profissional); e a segunda parte, também de dez questões, sendo a maioria descritivas, versava sobre a temática central do questionário, a N\&N. O questionário foi respondido de maneira virtual, baseado no modelo Google Formulário $\left(\text { Google Forms }{ }^{\circledR}\right)^{7}$.

Os professores colaboradores do estudo foram definidos segundo os seguintes critérios: estar vinculado a instituições educacionais públicas e/ou privadas de ensino médio ou superior e atuar no ensino de ciências ou matemática nestes níveis de ensino. Esses professores foram convidados a participar da pesquisa por meio de carta-convite, que foi enviada para o e-mail pessoal dos professores e/ou para o e-mail das listas de grupos de discussão; e-mails de coordenações ou instituições de educação básica e superior e programas de pós-graduação, endereços estes os quais os autores da pesquisa possuíam ou faziam parte ou obtiveram com outros contatos e colegas de profissão no decorrer da pesquisa. Por fim, utilizamos uma rede pessoal de contatos para o envio do convite, além de convidarmos/solicitarmos e autorizamos que estes replicassem o convite em sua rede de contatos. $O$ convite também foi socializado usando-se a rede social Facebook ${ }^{\circledR}$, por meio de um grupo fechado ${ }^{8}$, no qual somente os participantes interessados no tema e após serem aceitos no grupo poderiam interagir.

Após a divulgação da pesquisa e envio dos convites, quarenta e oito professores de diversas áreas do conhecimento, de quatro estados brasileiros (RJ, RS, SC e SP) responderam ao questionário. Depoimentos estes que foram considerados na primeira etapa da pesquisa

\footnotetext{
${ }^{7}$ Serviço do Google ${ }^{\circledR}$, vinculado ao Google Docs ${ }^{\circledR}$ que permite a edição colaborativa de documentos. O Google Formulário ou Forms ${ }^{\circledR}$ é de fácil apresentação, permitindo facilidade de uso e permitindo de forma organizada e simples organizar as respostas. Disponível em <https://www.google.com/intl/pt-BR/forms/about/>. Acessado em janeiro 2017.

${ }^{8}$ Qualquer pessoa pode encontrar o grupo e ver quem está nele. Somente membros podem ver as publicações. Disponível em < https://www.facebook.com/help/220336891328465\#What-are-the-privacy-options-forgroups $>$. Acessado em janeiro 2017.
} 
e que apresentamos algumas impressões sobre a inserção dos tópicos de N\&N no ensino. Entretanto, para a segunda etapa da pesquisa, na qual buscamos evidências das perspectivas de inserção dos tópicos de N\&N nas práticas profissionais destes professores nos níveis de ensino em que atuam, consideramos apenas as respostas concedidas pelos professores com formação inicial nas áreas de matemática e ciências da natureza, em exercício profissional em sala de aula no ensino médio e/ou superior. Deste modo, o material empírico do estudo constituiu-se das respostas dos questionários de vinte e cinco professores.

Por fim, a análise de dados, realizada na perspectiva da análise de conteúdo (BARDIN, 1979), consistiu na identificação de situações de ensino que sinalizavam a inserção dos tópicos de N\&N nas práticas dos professores depoentes. Estas situações, denominadas unidades de registro (BARDIN, 1979), foram agrupadas por proximidade dos temas, convergindo para as categorias de análise, as quais foram interpretadas em face aos referenciais sobre o ensino das ciências.

\section{Impressões sobre a inserção dos tópicos de Nanociência e Nanotecnologia no ensino}

$\mathrm{Na}$ primeira etapa de nossa análise, consideramos os dados provenientes dos questionários respondidos pelos quarenta e oito professores, etapa esta em que examinamos de maneira mais geral, a abordagem destes tópicos no ensino nos níveis médio e superior. Ao serem indagados se abordam os tópicos de $N \& N$ nas práticas de sala de aula ou se já trabalharam algum tema que se relaciona aos mesmos, 58,3\% dos professores afirmaram que nunca trabalharam este assunto. Contudo, observamos, especialmente nas respostas às questões descritivas em que relataram situações promovidas em sala de aula, que alguns dos professores participantes já desenvolveram atividades envolvendo estes tópicos. Ou seja, alguns professores, por não terem clareza sobre a que se referem às noções de $\mathrm{N} \& \mathrm{~N}$, afirmam não as abordar, o que não quer dizer que estes aspectos não estão sendo contemplados no ensino que realizam em sala de aula.

Considerando apenas os vinte e cinco professores, cujas respostas ao questionário são analisadas nesta etapa da análise de dados, verifica-se que, em relação à questão inicial do questionário, quatorze professores, representando 56\%, afirmam que nunca trabalharam com algum assunto que envolvesse os tópicos de $N \& N$, e onze, representando $44 \%$, afirmam que já trabalharam algum assunto sobre estes tópicos.

Por outro lado, destacamos que muitos dos professores que afirmam não abordar em suas práticas de sala de aula assuntos envolvendo estes tópicos, manifestaram curiosidade pelo tema, bem como pré-disposição para aprofundar seus conhecimentos e, assim, propor melhorias futuras nas práticas de sala de aula.

Relativamente aos professores que afirmam ter trabalhado algum assunto envolvendo a $N \& N$, as respostas por eles fornecidas indicam que para esses professores as áreas do conhecimento em evidência são as ciências da natureza (biologia, física e química), engenharias, área da saúde, matemática (com destaque para estudo de cálculo diferencial e integral ao trabalhar com a noção do infinitésimo e limites) e a toxicologia. Além disso, referiram-se às inovações que consideram importantes à sociedade e acreditam que estas possam ter alguma relação com estes tópicos. 
Em resposta à uma questão que solicitava que os professores citassem exemplos de inovações da ciência e tecnologia, indiferentemente da área de formação, os participantes da pesquisa referenciaram exemplos e aspectos diversos, os quais foram organizados em três grupos principais: (1) Ciências naturais e matemática: materiais avançados aplicados à engenharia de materiais, materiais com alta resistência mecânica, microscopia (microscopia eletrônica de varredura - MEV e microscopia eletrônica de transmissão - MET), modelagem computacional, novos materiais (nanomateriais de carbono, substâncias utilizadas em tintas, substância para compor plásticos variados), nanocerâmicos, nanopolímeros, reforço estrutural e manipulação de características dos materiais, tabela periódica, tecnologia para manipulação/observação de átomos e pequenas moléculas (AFM e similares); (2) Ciências da saúde e ambiental: alimentos, cosméticos, desenvolvimento de medicamentos, estudo de células-tronco para o tratamento de doenças degenerativas, diagnóstico de doenças, medicamentos encapsulados, meio ambiente, microchips, micropróteses, nanofármacos, nanotoxicologia comparada, pílulas anticoncepcionais, produção de fármacos baseados em nanocápsulas; (3) Tecnologia e sociedade: aparelhos de ultrassonografia, aplicação da hidrofobia, carros, eletrônicos, equipamentos de informática (computadores), equipamentos tecnológicos (celulares, máquinas fotográficas), fibra ótica, sensores e placas eletrônicas, progressos tecnológicos, tecnologia aeroespacial, tecnologias, etc. Os exemplos e aspectos citados pelos professores são gerais, de modo que não sabemos se são abordados ou não em sala de aula, pois a pergunta do questionário não contemplava esta dimensão. Solicitava apenas exemplos de inovações, as quais obviamente estão ligadas à N\&N, e esperávamos que os professores as relacionassem a estes tópicos em questões de ensino.

Dessa forma, considerando as especificidades dos exemplos que, mediante o agrupamento que realizamos, constituíram estes três grupos, destacamos que na perspectiva dos professores as inovações nas áreas das ciências (biologia, física e química) e matemática, envolvem processos específicos da área da ciência da natureza e matemática e no desenvolvimento de novos produtos e materiais, normalmente vinculadas a pesquisa em laboratórios específicos e produção industrial para este fim. As inovações na área da ciência da saúde e ambiental englobam estudos avançados na área da saúde, alimentação e meio ambiente, contemplando o desenvolvimento de novos fármacos, cosméticos e equipamentos, como próteses, auxiliando em diagnósticos mais precisos de doenças e, consequentemente, em seu tratamento. As inovações relativas à tecnologia e sociedade, por sua vez, integram soluções tecnológicas que são incorporados pela sociedade, afetando em sua organização e desenvolvimento e requisitando novas medidas e soluções para atender a demandas da sociedade contemporânea.

Ao serem questionados sobre quais conteúdos fazem parte da ementa dos componentes curriculares que ministram em sala de aula, seja no ensino médio e/ou superior, nos quais o professor poderia abordar tópicos de N\&N, eles destacaram diversas possibilidades: capilaridade, ciência da computação, eletricidade e eletromagnetismo, citologia, diversos elementos químicos, eletrônica, energia de ativação, engenharia ambiental, equações diferenciais, estruturas carbônicas, farmacologia, física moderna e contemporânea, física radiológica (os equipamentos de exames de diagnóstico por imagem genética), geometria, hidrostática, histologia, matemática - escalas, meio ambiente e legislação, microbiologia orgânica e formação de complexo inorgânicos em química inorgânica, polímeros, química (interações interatômicas e intermoleculares), robótica, tópicos relacionados a força e resistência de materiais, miniaturização de circuitos eletrônicos, entre outros. Acrescentaram que podem trabalhar a relação 
entre grandezas físicas que estão presentes na constituição de dispositivos de N\&N na abordagem de funções, limites, derivadas e integrais.

Por outro lado, alguns professores afirmaram não possuir conhecimentos suficientes para promover tais abordagens em sala de aula, e outros que têm receio em abordar estes tópicos por se tratar de assuntos complexos. Um dos professores diz, cautelosamente, que "precisaria analisar com calma" e outro diz que "acho que sim, mas não sei como". Esse aspecto é ressaltado por outro professor ao dizer que "não" trabalharia estes tópicos por não estar preparado para abordá-los.

Outros professores não especificaram qualquer componente curricular, mas sugerem o nível de ensino e cursos em que é possível abordar esta temática. Um professor afirma que "em Física Básica que trabalho, poderia trabalhar mais em nivel de pesquisa para ampliação de conbecimentos, ou seja, não teria como desenvolver nada prático, pelo menos em minha instituição". E complementa que "se fosse professor de Quimica com certeza, seria possivel trabalhar, como de fato em minha Instituição os professores de Quimica trabalham principalmente em associação com o Curso de Farmácia”.

Portanto, os dados evidenciam que existem limitações impostas por algumas instituições de ensino que acabam interferindo negativamente na possibilidade de inserção dos tópicos de N\&N no ensino básico. Dessa forma, mesmo que o professor tenha predisposição na inserção destes tópicos na sua prática de sala de aula, não poderia fazê-lo em virtude dessa limitação institucional.

Por outro lado, os professores destacam que a única forma de trabalhar com esses tópicos nas instituições que limitam a sua inserção no ensino, seria que cada docente ministrasse aulas em um componente curricular específico e em um determinado curso de nível superior. Neste caso, as instituições acabam por permitir tal ação no ensino, isto é, o ensino de tópicos ficaria relegado somente à autonomia didático-pedagógica que o professor possui em sala de aula. Também, para esses professores, somente no ensino superior é que os tópicos de N\&N poderiam ser apresentados aos estudantes e, consequentemente, aprofundados em suas ações voltadas a formação de nível superior.

Outros professores, em contrapartida, percebem a relação interdisciplinar do ensino desses tópicos, aspecto este que favorece a inserção dos mesmos no ensino. Esta inserção pode se dar através de projetos interdisciplinares, que venham despertar a curiosidade dos estudantes ou mesmo mediante a apresentação de alguns tópicos de $\mathrm{N} \& \mathrm{~N}$, cuja aplicações são facilmente identificadas no cotidiano.

Estes aspectos são ressaltados nas respostas de alguns professores quando afirmam que "pode-se trabalhar de maneira interdisciplinar", uma vez que em "qualquer momento possa se falar em nanociência", por meio de "projetos que abordam a temática da nanociência e nanotecnologia, explorando conceitos e relações matemáticas associadas aos mesmos". E quando afirmam que "partindo da curiosidade dos alunos, mas principalmente em projetos que levem o aluno a despertar seu interesse e curiosidade sobre nano". Além disso, alguns professores acreditam que a abordagem de assuntos envolvendo

\footnotetext{
${ }^{9}$ Os destaques entre aspas ("') são trechos retirados das respostas obtidas no questionário. Minimamente foram realizadas correções de ortografia e/ou concordância, quando necessário, para manter a coerência e coesão textual, porém as alterações realizadas não mudaram a ideia apresentada pelos professores.
} 
estes tópicos em sala de aula somente é possível ocorrer em alguns anos específicos do ensino médio ou ao longo do ensino superior, normalmente nos anos finais de cada nível de ensino.

Por outro lado, a maioria deles, dezessete professores, afirmam que é possível abordar estes assuntos a qualquer tempo no ensino médio e/ou superior, isto porque "os alunos têm acesso a tecnologias muito cedo, dominando-os de forma ampla" e ainda porque "são assuntos que possuem relação direta" entre si. Acrescentam que estes temas estão "presentes em nosso cotidiano", principalmente por "serem assuntos que envolvem inovações tecnológicas" e afetam na "qualidade de vida" das pessoas.

Dessa forma, os professores consideram possíveis e adequados que "princípios básicos podem ser tratados já muito cedo" nos primeiros níveis de ensino, ou seja, mediante algumas "adaptações poderia ser abordado em qualquer série", "aplicável em qualquer tipo de ensino e nivvel", "variando desde o nivel básico (pesquisa bibliográfica) até um estudo aplicado, no caso de nivel superior e área afim". Também evidenciam que esses tópicos têm relação com "a educação cientifica e tecnológica", pois estão "inseridas em nosso cotidiano" e, portanto, "estão inseridas neste contexto".

Consideram, para além disso, que estes tópicos estão "associados a maioria das inovações que têm modificado as atividades sociais e profissionais das pessoas e que, da mesma forma, têm ampliado as possibilidades de prevenir e/ ou controlar fenômenos naturais (por exemplo os climáticos), bem como combater doenças e epidemias, o que tem aumentado a expectativa de vida das populações". Ou seja, de acordo com os professores "trata-se da forma de abordagem que os alunos têm conhecimentos" e, portanto, "é interessante" desenvolver este tema em sala de aula. Porém, admitem que ainda não o fazem na prática por razões diversas, mas não destacam os motivos pelos quais não concretizam essa inserção.

De maneira complementar, dois professores, além de considerarem viável a abordagem de N\&N no ensino realizado em sala aula, propõem diversos assuntos e situações em que estes tópicos podem ser abordados. Eles afirmam que acreditam que estes tópicos podem ser abordados na "representação geométrica para estudar estruturas microscópicas que fazem parte das nanociências e nanotecnologias", e que "devem existir algumas reações com o ensino dos cálculos que são realizados para obter os resultados em nanotecnologias (mas eu não tenho conbecimento)".

Portanto, ao examinarmos as impressões gerais dos professores sobre a abordagem dos tópicos de $\mathrm{N} \& \mathrm{~N}$, evidenciamos posturas contrárias e contraditórias. Contrárias porque há professores que consideram possível abordar estes tópicos tanto no ensino médio quanto superior e outros que acham que não é possível. E contraditória porque alguns professores dizem que nunca abordaram estes assuntos, mas nas suas respostas às questões que versavam sobre as práticas de sala de aula indicam que desenvolvem algumas atividades que contemplam estas perspectivas. Contraditórias, ainda, porque há professores que sugerem que estes tópicos sejam abordados apenas no ensino superior, o que evidencia uma incoerência em relação aos objetivos/práticas da educação escolar e as mudanças advindas das ciências e tecnologias que impactam na vida das pessoas e nas atividades profissionais.

\section{Perspectivas de inserção dos tópicos de Nanociência e Nanotecnologia no ensino}

Para esta etapa da análise, organizamos o material empírico de acordo com os eixos temáticos focados nas questões do questionário relacionadas ao Material didático, diretrizes curriculares nacionais (DCN) (BRASIL, 2012, 2013, 2015) e Parâmetros curriculares nacionais (PCN) 
(BRASIL, 2000a, 2000b, 2002) e Estratégias Pedagógicas usadas pelos professores. Por estratégias pedagógicas nos referimos às diversas dinâmicas de sala de aula promovidas pelo professor para o desenvolvimento do conteúdo curricular, por exemplo, o desenvolvimento de projetos, realização de pesquisa bibliográfica, realização de experimentos, utilização e produção de audiovisuais, aula dialogada, explicação e demonstração, apresentação de seminários elaborados pelos alunos etc.

Os quadros apresentados na sequência sistematizam todas as respostas fornecidas para as seguintes questões: em relação aos materiais didáticos da sua área utilizados por você na preparação das atividades para sala de aula, disponiveis na internet ou em versões impressas, você procura apoio nesses materiais? Ao preparar as atividades para sala de aula, você procura apoio nas DCN e nos PCN? Quais as estratégias pedagógicas você utiliza em suas aulas para abordar tópicos de N\&N? (TOMKELSKI, 2017).

A partir da análise realizada sobre este material, identificamos abordagens desenvolvidas pelos professores em suas práticas, por meio das quais os tópicos de $\mathrm{N} \& \mathrm{~N}$ vêm sendo desenvolvidos no ensino médio e superior. Tais abordagens foram agrupadas em três temáticas centrais: abordagem de base para desenvolver um conteúdo curricular; abordagem integrada a um conteúdo curricular, e abordagem suplementar às atividades de sala de aula.

$\mathrm{Na}$ Temática 1, Abordagem de base para desenvolver um conteúdo, consideramos as respostas que contemplam situações relacionadas ao planejamento das atividades de sala de aula, para as quais os professores costumam apoiar-se em materiais didáticos disponíveis na sua área de atuação e nas DCN e PCN (BRASIL, 2000a, 2000b, 2002, 2012, 2013, 2015). Para tanto, levamos em conta também as descrições dos professores sobre as estratégias pedagógicas utilizadas no planejamento das aulas, conforme indicado no Quadro 1.

Ao serem questionados se utilizam materiais didáticos disponíveis em versões digitais (internet) ou impressa no planejamento das aulas, a maioria dos professores destacou que sim e outros disseram que utilizam algumas vezes. Entretanto, um professor afirma que não utiliza estes materiais didáticos, específicos da sua área de atuação, por entender que eles não contemplam as necessidades de aprendizagem dos alunos, ao mesmo tempo em que estão desconectados da realidade das escolas e da sala de aula.

Os demais professores afirmam que sempre utilizam e aqueles que dizem que costumam consultar estes materiais algumas vezes, ressaltam que estes recursos, seja em formato digital ou impresso, são usados para pesquisar algum aspecto relacionado ao conteúdo que pretendem desenvolver em sala de aula. Muitos professores afirmam que utilizam como forma de exemplificação ou demonstração, recorrendo, muitas vezes a recursos digitais tais como apresentação de slides, constituindo assim, uma base conceitual para explicações e reflexões sobre a temática em estudo. Da mesma forma, as respostas relacionadas às DCN e os PCN (BRASIL, 2000a, 2000b, 2002, 2012, 2013, 2015) fazem referência a estes aspectos, visto que têm sido utilizados no planejamento da aula.

Ao serem indagados se consultam as DCN e os PCN para preparar as atividades de sala de aula, a maioria dos professores afirma que sim ou pelo menos às vezes, o que representa uma informação importante, uma vez que ao utilizar esses documentos o professor acaba por inserir no seu planejamento tópicos envolvendo a $N \& N$. Ou seja, posto que tais documentos contemplam estes tópicos em suas orientações, muitas vezes introduzindo-os em situações em que estes encontram-se aplicados, consideramos que de forma gradual e, às vezes, não consciente, as abordagens dos professores do ensino médio e superior têm contemplado a referida temática. 
Quadro 1 - Respostas das questões sobre material didático, Diretrizes e Parâmetros Curriculares Nacionais e estratégias pedagógicas utilizadas na preparação das atividades para sala de aula

\begin{tabular}{|c|c|c|}
\hline Material Didático & $\begin{array}{l}\text { Diretrizes Curriculares (DCN) e } \\
\text { Parâmetros Curriculares (PCN) }\end{array}$ & Estratégias Pedagógicas \\
\hline $\begin{array}{l}\text { Apresentação de slides. } \\
\text { Apresento para a turma em slides } \\
\text { e uso como exemplo. } \\
\text { Buscando novas descobertas } \\
\text { e relações com o conteúdo } \\
\text { abordado. } \\
\text { Como base de conteúdos, } \\
\text { exercícios e textos que são } \\
\text { levados aos alunos. } \\
\text { Internet e livros. } \\
\text { [Material] impresso. } \\
\text { Lendo [artigos científicos] e } \\
\text { fundamentando as minhas } \\
\text { explicações e reflexões sobre essa } \\
\text { temática. } \\
\text { [Recorro a materiais didáticos } \\
\text { para] seleção das atividades. } \\
\text { [Recorro a materiais didáticos } \\
\text { para] consulta. } \\
\text { [Recorro a materiais didáticos } \\
\text { para] preparar aulas. } \\
\text { Planejando as aulas de maneira } \\
\text { que a internet complemente as } \\
\text { teorias dos livros e faça com que } \\
\text { a didática seja mais atrativa para } \\
\text { os alunos. } \\
\text { [Recorro a materiais didáticos } \\
\text { para o] preparo de aulas e } \\
\text { demonstrações } \\
\text { Tanto para uso próprio } \\
\text { (preparação) quanto como } \\
\text { indicação bibliográfica aos } \\
\text { alunos. }\end{array}$ & $\begin{array}{l}\text { Baseio-me na minha experiência de } \\
\text { sala de aula. } \\
\text { Me baseio nos livros e apostilas } \\
\text { que temos acesso na escola e } \\
\text { nas questões que os vestibulares } \\
\text { cobram. } \\
\text { Normalmente sigo o plano de } \\
\text { curso estabelecido e elaboro a } \\
\text { abordagem que acho conveniente. } \\
\text { Pois com o corre-corre das } \\
\text { atividades em sala de aula e } \\
\text { extraclasse não se tem tempo. } \\
\text { Por não ter esse costume, nunca } \\
\text { consultei no preparo de aulas e } \\
\text { materiais. } \\
\text { Porque não há muitas orientações } \\
\text { sobre essa temática nesse } \\
\text { documento, embora eles já } \\
\text { contemplem a abordagem } \\
\text { desse tema, o que é um avanço } \\
\text { considerando-se que foram } \\
\text { elaborados no final dos anos } 1990 \\
\text { e que essas ideias (nanociência e } \\
\text { nanotecnologia) ainda são poucas } \\
\text { (ou nada) percebidas pelas pessoas } \\
\text { em geral. O que quero dizer é que } \\
\text { as pessoas, de um modo geral, } \\
\text { ainda não têm clareza do que são } \\
\text { essas ideias e que as inovações que } \\
\text { delas derivam estão impregnadas } \\
\text { em tudo que fazemos nas nossas } \\
\text { atividades cotidianas. }\end{array}$ & $\begin{array}{l}\text { Ainda não utilizo de } \\
\text { maneira ampla, mas uso } \\
\text { nas aulas que envolvem o } \\
\text { estudo dos átomos. } \\
\text { Pesquisa }\end{array}$ \\
\hline
\end{tabular}

Fonte: elaborado pelos autores.

Por outro lado, alguns responderam que não procuram apoio nas DCN e PCN, pois dizem não terem percebido muita orientação ou informação relacionada a essa temática nesses documentos, embora seja contemplada indiretamente e também porque ainda não possui muito destaque na sociedade. Essa ideia fica evidente na fala de um professor quando afirma que "o que quero dizeré é que as pessoas, de um modo geral, ainda não têm clareza do que são essas ideias e que as inovações que delas derivam estão impregnadas em tudo que faz̧emos nas nossas atividades cotidianas". 
Alguns professores, por sua vez, afirmam que utilizam apenas os livros didáticos e apostilas disponibilizados pelas instituições educacionais, pois acreditam que estes recursos já contemplam as DCNs e os PCNs. Outros acreditam que sua experiência de sala de aula é, por si só, suficiente para realizarem o planejamento das aulas, pois entendem que os anos de experiência lhes proveram as informações e os conhecimentos necessários para planejar as aulas e desenvolver os conteúdos. Por fim, há aqueles que dizem não abordar estas temáticas por terem que centralizar sua atenção em situações pontuais, envolvendo assuntos específicos, que são normalmente cobrados em processos seletivos, como os vestibulares; ou por seguirem um plano de curso estabelecido e elaborado anteriormente; ou que não o fazem por falta de tempo e das demais atividades cotidianas.

Além disso, os professores quando questionados se observam orientações relativas à esta temática nos documentos oficiais e nos materiais didáticos de sua área de atuação, afirmam, na sua grande maioria, que percebe a presença da temática da N\&N e destacam exemplos. Estes exemplos estão relacionados ao estímulo ao "uso de novas tecnologias", "equipamentos eletrônicos", "desenvolvimento de tecnologia relacionadas a medicamentos e alimentos", "programação" ou como "um conhecimento cientifico" que "serve para explicar o funcionamento do mundo". Outros exemplos citados são mais específicos por referenciarem os "nanopolímeros" e a "biotecnologia". Outro professor destacou trechos de documentos específicos de um determinado curso de nível superior, e ressalta que "com o avanço tecnológico, novas perspectivas se apresentam para o profissional farmacêutico, quais sejam: farmacogenética, planejamento e produção de novos fármacos, biotecnologia, nanotecnologia, toxicologia pré-clínica e clínica, atenção farmacêutica, fármaco-economia, farmacovigilância, entre outras".

No âmbito da educação básica, um professor destaca, referenciando às DCN, que "não se pode, pois, ignorar o que se vive: o avanço do uso da energia nuclear; da nanotecnologia; a conquista da produção de alimentos geneticamente modificados; a clonagem biológica", evidenciando que possui conhecimento das Orientações Curriculares que lhes servem de base para realizar o planejamento das aulas.

Por outro lado, alguns professores dizem não terem percebido a presença desta temática nos documentos oficiais e material didático de sua área de atuação profissional. Ao serem questionados sobre o que os levou a essa constatação, afirmam que "o tema começa a surgir, principalmente em textos didáticos especificos", portanto está ainda muito restrito a um pequeno grupo de pessoas. Outros afirmam que o motivo disso é o fato de que as pessoas que contribuíram na elaboração destes documentos oficiais "não tinham nenhum conbecimento a respeito do tema e de como vincular o mesmo ao ensino", ou seja, "desconhecimento ou falta de interesse dos organizadores". E outros admitem desconhecer se a temática está presente nos documentos oficiais, sugerindo que a leitura destes documentos oficiais não foi clara o suficiente para perceber a presença destes tópicos, ou que não perceberam a presença do termo "Nanociências" nos documentos. Isso fica evidente na fala de um professor ao afirmar que "em alguns trechos desses documentos se faz referência as inovações e tecnologias, mas não especificamente a nanociência".

Em relação às estratégias pedagógicas adotadas em aula, a maioria dos professores afirma que não aborda ou não utiliza nenhuma estratégia pedagógica no planejamento de suas aulas. Apenas dois professores destacaram aspectos relacionados a essa temática. Um deles afirma que utiliza como forma de "pesquisa", pois assim como destacado no material didático, a pesquisa é parte fundamental da abordagem de base para desenvolver o conteúdo curricular, e o outro destaca que não utiliza ainda "de maneira ampla". Ou seja, acaba apenas por utilizar em situações pontuais como "nas aulas que envolvem o estudo dos átomos". 
Relativamente à Temática 2, Abordagem integrada a um conteúdo curricular, consideramos as respostas que apresentam elementos em que o professor indica que utiliza materiais didáticos e estratégias pedagógicas no desenvolvimento do plano de trabalho (plano de aula) na prática de sala de aula. Tais elementos, que são destacados no Quadro 2, referemse às respostas dos professores sobre a utilização de materiais didáticos, documentos legais e estratégias pedagógicas no desenvolvimento do ensino. Esclarecemos que os professores que responderam negativamente à essa questão, ou seja, afirmam que não utilizam esses recursos no planejamento das suas atividades, foram destacados na discussão da temática anterior.

Quadro 2- Respostas das questões sobre material didático e estratégias pedagógicas utilizadas na preparação das atividades para sala de aula

\begin{tabular}{|l|l|}
\hline \multicolumn{1}{|c|}{ Material didático } & \multicolumn{1}{c|}{ Estratégias pedagógicas } \\
\hline Como temas de & Através da sensibilização e demonstração da presença e importância \\
discussão em sala de & delas em nossas vidas. \\
aula, abordagem de & Aulas expositivas e dialogadas. \\
tecnologias, curiosidades. & Estudante compartilha aplicações veiculadas nas diversas mídias. \\
Preparo de aulas e & Exemplificação. \\
demonstrações. & Explicações sobre algumas ideias e seus inventos, reflexões sobre o \\
Para retirar exercícios, & modo como essas inovações modificam as nossas atividades. \\
fotos para apresentação & Leituras sobre novas invenções e as expectativas a ela associadas, \\
visual e vídeos. & bem como sobre os rumos da humanidade em face as mudanças que \\
Pesquisas, slides. & decorrem desse desenvolvimento. \\
Seminários em sala de & Leituras de descobertas e inovações tecnológicas e em algumas áreas \\
aula. & específicas, como a da saúde. \\
Vídeos. & Problematização. \\
Exercícios e etc. & Programação robótica \\
& Textos retirados de revistas, sites, o que for notícia e novidade na área, \\
& sempre que pertinente é discutido em sala de aula. \\
& Textos, reportagens, curiosidades, projetos. \\
& Utilizaria pesquisa e seminários \\
\hline
\end{tabular}

Fonte: elaborado pelos autores.

Em relação aos materiais didáticos da área de atuação, virtuais ou impressos, os professores destacam que normalmente utilizam, no decorrer da prática da sala de aula, para a realização de "pesquisas" pelos estudantes ou para sugerir "temas" que possam ser discutidos com os alunos, normalmente envolvendo questões sobre as "novas tecnologias e curiosidades" que os alunos possuem sobre as aplicações das tecnologias. Com isso acabam por incentivar o debate coletivo sobre estes aspectos e o trabalho com "seminários em sala de aula". Também afirmaram que buscam diversificar a aula com outros recursos, dentre eles "videos", "imagens", "demonstrações", "apresentações visuais" e "exercícios". Em outras palavras, recorrem aos recursos áudio visuais para concretizar as atividades previamente planejadas e alcançar os objetivos estabelecidos para as mesmas. 
Em relação às estratégias pedagógicas utilizadas pelos professores, foram referenciadas, principalmente, "aulas expositivas e dialogadas", assim como referiram estratégias específicas, tais como "programação e robótica". Ressaltam que, para promover aulas dialogadas, propõem interações com os estudantes como uma forma de levá-los a compartilhar "aplicações vinculadas nas diversas midias", estimulando-os a trazer para a aula "assuntos interessantes", os quais possam servir de base à "problematização", à "exemplificação" e à "pesquisa" escolar. Tais atividades podem alcançar sua culminância com "seminários" sobre os mais diversos assuntos envolvendo estes tópicos.

Outros professores destacam que utilizam estratégias de "sensibilização e demonstração da presença e importância delas em nossas vidas" ou "apenas citações pontuais que se relacionam ao assunto", sem aprofundar o entendimento ou instigar a pesquisa e debate. Ou seja, utilizam-se de "explicaçôes sobre algumas ideias e seus inventos, reflexões sobre o modo como essas inovacôes modificam as nossas atividades".

Para além disso, os professores acrescentam que utilizam "textos informativos", normalmente retirados de "revistas e sites", "reportagens", "curiosidades", "noticias", "leituras de descobertas e inovaçoes tecnológicas em algumas áreas", recursos estes que são usados para desenvolver alguns conteúdos curriculares nas classes em que lecionam. Essas estratégias têm propiciado situações que os levam ao desenvolvimento de "projetos" relacionados a área de atuação em sala de aula. Este aspecto é evidenciado na resposta de um professor ao afirmar que "sempre que pertinente é discutido em sala de aula" algo interessante sobre o assunto da aula.

De acordo com outra resposta, com esta dinâmica de aula espera-se formar estudantes capazes de realizar as mais diversas formas de "leituras sobre novas invencõoes e as expectativas a ela associadas, bem como sobre os rumos da humanidade em face às mudanças que decorrem desse desenvolvimento".

Portanto, com relação à abordagem integrada a um conteúdo curricular, o estudo mostra que há diversas iniciativas, algumas intencionais e outras ainda de forma inconsciente (não intencional) por parte dos professores em promover atividades de sala de aula que contemplam os tópicos de N\&N. E tais atividades, de maneira predominante, sugerem o desenvolvimento de leituras, discussões e pesquisas em sala de aula, assim como o uso de recursos audiovisuais que oportunizam aos alunos perceberem a presença e o impacto dos produtos gerados pela N\&N na sociedade contemporânea.

Por fim, além das abordagens discutidas, as respostas dos professores evidenciaram situações que promovem a abordagem suplementar às atividades de sala de aula, que constituiu a Temática 3, conforme indicado no Quadro 3.

Assim, baseados nas respostas dos professores sobre as estratégias e materiais de apoio utilizados por eles, buscamos evidenciar ações relacionadas às atividades que possam ser realizadas pelos estudantes fora do espaço da sala de aula, com o intuito de promover oportunidades de aprofundar seus conhecimentos sobre os assuntos abordados. De acordo com as informações apresentadas no quadro anterior, verificamos que a principal ação adotada pelos professores se refere às sugestões/indicações para auxiliar no direcionamento do foco de atenção dos estudantes de modo a levá-los a estudarem um determinado assunto envolvendo os tópicos de N\&N fora do ambiente de sala de aula e, consequentemente, sem a presença e a participação do professor no direcionamento das análises e discussões. 
Quadro 3 - Respostas das questões sobre material didático e estratégias pedagógicas utilizadas na preparação das atividades para sala de aula

\begin{tabular}{|c|c|}
\hline Material didático & Estratégias pedagógicas \\
\hline $\begin{array}{l}\text { Texto dissertativo ou de caráter informativo e } \\
\text { questionador. } \\
\text { Estudo complementar e sugestões de atividades. } \\
\text { São livros textos para estudo dos alunos e artigos } \\
\text { complementares aos temas trabalhados. } \\
\text { Tanto para uso próprio (preparação) quanto } \\
\text { como indicação bibliográfica aos alunos. }\end{array}$ & $\begin{array}{l}\text { Incentivo à leitura de bibliografia. } \\
\text { Leituras de descobertas e inovações tecnológicas } \\
\text { e em algumas áreas específicas, como a da saúde. } \\
\text { Textos, reportagens, curiosidades, projetos } \\
\text { Textos informativos. } \\
\text { Utilizaria pesquisa e seminários. }\end{array}$ \\
\hline
\end{tabular}

Fonte: elaborado pelos autores.

Segundo as respostas dos professores, suas ações são direcionadas para "indicação bibliográfica" adequadas aos estudantes, considerando nível e série, proporcionando um "estudo complementar e sugestão de atividades". Para isso, sugerem "leituras de descobertas e inovaçoes", "textos, reportagens, curiosidades, projetos" e "texto dissertativo ou de caráter informativo e questionador". Também propõem "pesquisas e seminários", "livros textos" e "artigos complementares aos temas trabalhados", sempre buscando o "incentivo à leitura" e aprofundamento do conhecimento dos estudantes.

Percebemos que as respostas dadas pelos professores, acabam por convergir em duas perspectivas: uma voltada a questões educacionais e outra que considera os aspectos sociais, econômicos e ambientais. Nessa perspectiva o estudo indica que as práticas profissionais dos professores têm contemplado uma importante dimensão, a qual se refere às atividades suplementares de sala de aula. Por meio destas atividades os professores buscam incentivar os seus estudantes a aprofundarem os conhecimentos sobre o assunto curricular e a desenvolverem a capacidade de pesquisar, produzir situações de aprendizagem e a formular suas conclusões.

\section{Discussão das perspectivas}

Por meio desta pesquisa, buscamos elementos que evidenciássem o modo como os professores das áreas de matemática e ciências da natureza (biologia, física e química), que atuam profissionalmente em instituições educacionais brasileiras, propõem o ensino de tópicos de N\&N nas práticas de sala de aula.

A partir da análise que realizamos observamos que os documentos legais - Lei de Diretrizes e Bases, DCN, PCN, Orientações Curriculares, Resoluções e Pareceres (BRASIL, 1996, 2000a, 2000b, 2002, 2006, 2012, 2013, 2015) - sugerem que os processos educativos/ formativos no ensino médio e superior busca promover a formação para a cidadania, apoiando-se em conhecimentos do mundo físico e natural, bem como da realidade vivenciada pelos estudantes no ambiente social e político (BRASIL, 1996). Esse aspecto, de acordo com a Lei de Diretrizes e Bases (LDB) 9394/96, pode ser alcançado com a compreensão, nos processos produtivos, dos fundamentos científicos-tecnológicos relacionados à teoria e prática de cada componente curricular (BRASIL, 1996). Assim, espera-se que o estudante alcance, além do desenvolvimento como pessoa humana, também uma formação ética, um desenvolvimento 
intelectual e crítico, desenvolvimento do espírito científico e o pensamento reflexivo (BRASIL, 1996).

Sobre esse aspecto, nosso estudo mostra que os professores participantes demostram predisposição em aprender e inserir esses tópicos em suas práticas de sala de aula, ao mesmo tempo em que reconhecem a necessidade de promover uma formação mais científica e tecnológica, bem como inserir a escola e a universidade no contexto social, político e econômico em que vivem. Nessa perspectiva, a necessidade de uma formação sólida, baseada no conhecimento e na ética, passa a ser uma questão fundamental para o sistema educacional e deve ser encarado com um dos grandes objetivos na elaboração de políticas públicas educacionais.

Portanto, os professores estão dispostos a participar efetivamente na construção de uma formação que contemple, não somente a alfabetização científica e tecnológica, mas principalmente formar cidadãos letrados cientificamente. Essa visão vem ao encontro da compreensão de Vestena e Nicoletti (2016) que afirmam que alfabetizar cientificamente não significa apenas dar acesso aos conceitos provenientes das ciências, mas é preciso alcançar um nível de alfabetização que seja capaz de promover a decodificação da realidade empreendendo autonomia e responsabilidade social dos envolvidos no processo, isto é, promover o letramento científico.

Além disso, nosso estudo mostra que as Diretrizes Curriculares e os Parâmetros Curriculares, e suas Orientações (BRASIL, 2000a, 2000b, 2002, 2012, 2013, 2015), apresentam em diversos momentos, indiretamente, a inserção de tópicos de N\&N no ensino médio e superior ao se referir a tecnologia e as inovações dela decorrentes. Entretanto, é infrequente a presença da nomenclatura nano em seu texto, surgindo normalmente como exemplificação em algum componente curricular específico mencionado.

Do ponto de vista dos professores colaboradores do estudo, as práticas pedagógicas que promovem são baseadas nas orientações presentes nos documentos curriculares nacionais e, especialmente, nas abordagens apresentadas nos livros didáticos. Esta compreensão levou alguns professores a concluírem que os tópicos de $\mathrm{N} \& \mathrm{~N}$ se fazem presentes em suas práticas profissionais. Entretanto, esta compreensão não foi evidenciada por uma parte dos professores participantes, aproximadamente um terço deles, os quais indicam em suas respostas que não abordam estes tópicos em sala de aula. Mediante estes aspectos, nosso estudo mostra que a inserção dos tópicos de $N \& N$, considerando-se o contexto de atuação dos professores participantes e as condições de trabalho, é fortemente influenciada pelos materiais didáticos que esses profissionais têm acesso, assim como por outras fontes de consulta disponíveis, tais como a internet e materiais suplementares disponíveis nas instituições de ensino. Concluímos, portanto, que o acesso a distintos recursos pedagógicos e documentos curriculares favorece a introdução de mudanças educacionais nas práticas profissionais dos professores, especialmente no que diz respeito à inserção de novas temáticas e abordagens de sala de aula, a exemplo dos tópicos de N\&N e modos de desenvolvê-los em sala de aula.

No âmbito do nosso estudo, conforme relatos dos professores, as abordagens associadas e estes tópicos, algumas vezes, buscam promover o embasamento para o processo de ensino que é desenvolvido em sala de aula, na medida em que os alunos realizam leituras ou pesquisas previamente à aula. Em outros casos, a abordagem ocorre no processo de 
desenvolvimento do conteúdo curricular em sala de aula. E, outras vezes ainda, a abordagem destes tópicos concretiza-se numa perspectiva de suplementação do trabalho realizado em sala, na medida em que os alunos realizam atividades que transcendem as atividades de sala de aula e realizam estudos para além daqueles referenciais contemplados pelo professor.

\section{Considerações finais}

O estudo mostra que a inserção dos tópicos de $\mathrm{N} \& \mathrm{~N}$ nas práticas de sala de aula, no ensino médio e superior vem se concretizando, uma vez que estes tópicos são contemplados nas DCN, nos materiais didáticos disponibilizados aos professores, nas diversas fontes de informação e de conteúdo acessadas pelos professores, bem como nas abordagens que muitos deles realizam em sala de aula. Relativamente às situações de ensino, constatamos que os professores se mostram hesitantes em afirmar se abordam assuntos envolvendo estes tópicos em suas práticas de sala de aula, entretanto, ao relatarem algumas práticas acabam explicitando aspectos relacionados. Este aspecto é evidenciado ao confrontarmos a resposta da questão inicial, na qual a maioria dos professores afirma não inserir tópicos de $\mathrm{N} \& \mathrm{~N}$ em suas aulas, em relação às demais questões.

Por outro lado, os professores têm conhecimento sobre as recomendações e orientações preconizadas pelos documentos oficiais sobre a inserção destes tópicos no ensino e afirmam utilizá-los no planejamento das práticas de sala de aula. Acrescentam que encontram referências sobre este tema em diversos materiais didáticos consultados e que realizam pesquisas sobre o assunto para o planejamento das aulas, assim como destacam a necessidade do trabalho ser interdisciplinar nas escolas para favorecer a inserção da temática de N\&N nos mais diversos componentes curriculares; e quando instigam nos estudantes a curiosidade e incentivam a pesquisa como forma de complementar os saberes apresentados em sala de aula e em alguns casos, posteriormente, permitem a troca desses novos conhecimentos entre os estudantes no ambiente escolar.

Por fim, salientamos que este trabalho representa uma pequena fração do entendimento sobre o modo como os tópicos de N\&N estão sendo incorporados nas ações das escolas e universidades permitindo, ainda, uma série de investigações e aprofundamentos sobre o tema. Assim sendo, com os resultados encontrados, podemos concluir que existe amparo legal para que, estes tópicos sejam implementados nos programas curriculares, uma vez que a maioria dos professores já os inserem mesmo que discretamente em suas aulas. Existe uma demanda de inserção de tópicos mais específicos e aprofundados nos currículos escolares, principalmente nos cursos de nível superior, especialmente no que tange às necessidades sociais, econômicas e ambientais emergentes. Outro aspecto importante, diz respeito à predisposição dos agentes formadores para, primeiramente obterem a formação essencial e adequada e, posteriormente, formar os estudantes para contemplar essas demandas. Sobre isso, destaca-se a necessidade de formação (inicial e continuada) dos professores. Por fim, é fundamental que se valorize investimentos mais contundentes na área de educação para ensino, pesquisa e extensão, bem como em recursos humanos, visando à valorização dos profissionais de educação. 
Tomkelski, M. L.; Fagan, S. B.; Scremin, G.

\section{Agradecimentos}

Os autores agradecem o apoio financeiro parcial da Coordenação de Aperfeiçoamento de Pessoal de Nível Superior (CAPES).

\section{Referências}

BARDIN, L. Análise de conteúdo. Lisboa: Edições 70, 2011.

BRASIL. Lei $\mathbf{n}^{\circ}$ 9.394, de 20 de dezembro de 1996. Estabelece as diretrizes e bases da educação nacional. Brasília: Câmara dos Deputados, 1996. Disponível em: http://www2. camara.leg.br/legin/fed/lei/1996/lei-9394-20-dezembro-1996-362578-normaatualizada-pl. doc. Acesso em: 5 dez. 2016.

BRASIL. Resolução $\mathbf{n}^{\mathbf{0}}$ 2, de 30 de janeiro de 2012. Define diretrizes curriculares nacionais para o ensino médio. Brasília: ME, 2012.

BRASIL. Resolução $\mathbf{n}^{\mathbf{0}} \mathbf{2}$, de $\mathbf{1}^{\mathbf{o}}$ de julho de 2015. Define as diretrizes curriculares nacionais para a formação inicial em nível superior (cursos de licenciatura, cursos de formação pedagógica para graduados e cursos de segunda licenciatura) e para a formação continuada. Brasília: ME, 2015.

BRASIL. Ministério da Educação. Diretrizes curriculares nacionais gerais da educação básica. Brasília: Secretaria de Educação Básica, 2013.

BRASIL. Ministério da Educação. Orientações curriculares para o ensino médio: ciências da natureza, matemática e suas tecnologias. Brasília: Secretaria de Educação Básica, 2006.

BRASIL. Ministério da Educação. Parâmetros curriculares nacionais ensino médio: bases legais. Brasília: Secretaria da Educação Média e Tecnológica, 2000a. v. 1.

BRASIL. Ministério da Educação. Parâmetros curriculares nacionais ensino médio: ciências da natureza, matemática e suas tecnologias. Brasília: Secretaria da Educação Média e Tecnológica, 2000b. v. 3.

BRASIL. Ministério da Educação. PCN+ ensino médio: orientações educacionais complementares aos parâmetros curriculares nacionais ciência da natureza, matemática e suas tecnologias. Brasília: Secretaria da Educação Média e Tecnológica, 2002. v. 2.

CHIBENI, S. S. Introdução à filosofia da ciência. 2011; Disponível em: http://www. unicamp.br/ chibeni/textosdidaticos/textosdidaticos.htm. Acesso em: 10 nov. 2016

COMISSÃO EUROPEIA. Comunicação da comissão ao parlamento europeu, ao conselho e ao comité econômico e social europeu: segunda revisão regulamentar relativa a nanomateriais. Bruxelas: CE, 2012. Disponível em: http://ec.europa.eu/research/ industrial_technologies/pdf/policy/communication-from-the-commission-secondregulatory-review-on-nanomaterials_pt.pdf. Acesso em: 9 ago. 2019. 
CRESWELL, J. W. Investigação qualitativa e projeto de pesquisa: escolhendo entre cinco abordagens. 3. ed. Porto Alegre: Penso, 2014.

FILLIPPONI, L.; SUTHERLAND, D. Nanotechnologies: principles, applications, implications and hands-on activities: compendium for educators. Luxembourg: European Commission, 2013. Disponível em: https:// ec.europa.eu/research/industrial_technologies/ pdf/nano-hands-on-activities_en.pdf. Acesso em: 10 set. 2016.

MURRIELLO, S.; CONTIER, D.; KNOBEL, M. Desafios de uma exposição sobre nanociência e nanotecnologia. Journal of Science Communication, Trieste, v. 5, n. 4 , p. 1-11, 2006.

TOMA, E. H. O mundo nanométrico: a dimensão do novo século. 2. ed. São Paulo: Oficina de Textos, 2009.

TOMKELSKI. O ensino de tópicos de nanociência e de nanotecnologia na educação básica e superior: uma análise a partir das compreensões de professores. 2017. 209 f. Dissertação (Mestrado em Ensino de Ciências e Matemática) - Universidade Franciscana, Santa Maria, 2017.

VESTENA, R. F.; NICOLETTI, E. R. Alfabetização científica para ensinar e aprender. In: BOER, N.; ZANELLA, D. C.; PEIXOTO, S. C. (org.). Ensino e profissão docente: edição comemorativa aos 25 anos da Jornada Nacional de Educação. Santa Maria: Centro Universitário Franciscano, 2016. v. 1, p. 178-189.

ZANELLA, I.; FAGAN, S. B.; BISOGNIN, V.; BISOGNIN, E. Abordagens em nanociência e nanotecnologia para o ensino médio. In: SIMPÓSIO NACIONAL DE ENSINO DE FÍSICA, 18., 2009, Vitória. Anais [...]. Vitória: UFES, 2009. Disponível em: http://www. sbf1.sbfisica.org.br/eventos/snef/xviii/programa/lista_trabalho.asp?sesId=42. Acesso em: 11 mar. 2014.

Submetido em 03/07/2018. Aceito em 10/01/2019

Contato: Governo do Estado do Rio Grande do Sul, Secretaria da Educação (SE/RS), 15ª Coordenadoria Regional de Educação (CRE), Setor Pedagógico, Praça da Bandeira, 190, Centro, Erechim, RS, 99700-010. 
